\title{
Capsule Commentary on Gonzalo, et al., Impact of an Overnight Internal Medicine Academic Hospitalist Program on Patient Outcomes
}

\author{
Benji K. Mathews, M.D. \\ Department of Medicine, HealthPartners and University of Minnesota Medical School, Saint Paul, MN, USA.
}

J Gen Intern Med 30(12): 1850

DOI: $10.1007 / \mathrm{s} 11606-015-3414-3$

(c) Society of General Internal Medicine 2015

$\mathrm{T}$ his retrospective, interrupted time-series analysis by Gonzalo et al. evaluated the effect of an overnight academic hospitalist $(\mathrm{OAH})$ program on patient-level outcomes at a large university-based acute care hospital. ${ }^{1}$ The intervention consisted of a year-round overnight academic hospitalist program staffed by one hospitalist physician and coincided with the hours of the night float housestaff.

The study showed no significant change in their patientlevel outcomes including the average length of stay, inhospital mortality rate, 30-day readmission rate, and upgrades in care to intensive care unit.

The outcomes as described above were important to evaluate in this study. However, there are likely better components for measuring whether residents and supervising hospitalists were in fact impacting the health of patients. Patient-reported outcome measures (PROMs) are a helpful component of assessing whether clinicians are improving the health of patients. Unlike process measures, which capture provider productivity and adherence to the standards of recommended care, or patient experience measures, which focus on aspects of care delivery, PROMs seek to understand whether the services provided actually improved patients health and sense of well-being. ${ }^{2}$ For example, through the implementation of an $\mathrm{OAH}$ program, patients might be asked to assess their general health and satisfaction in care overnight. Moreover, it would seem that not only the patient-reported outcome measures but also a learner-reported outcome measure would show promising results. In the paper by Haber et al., increased overnight supervision enhanced the clinical value of the night float rotation, increased rates of attending contact during critical clinical decision-making, and improved perception of patient care. $^{3}$

Nighttime supervision is a key concept in medical education and is critical in ensuring safe and effective patient care. ${ }^{4}$ As noted by Hanson et al., nighttime education should be transformed in a way that maintains clinical productivity for both attending and resident physicians, integrates high-quality teaching and curricula, and achieves a balance between patient safety and resident autonomy. ${ }^{5}$ The results of the study are promising and helpful for programs as they aim to implement systems to ensure appropriate nighttime supervision. Further study is needed to assess the impact on broader patient outcomes.

Conflict of Interest: The author has no conflicts of interest with this article.

Corresponding Author: Benji K. Mathews, M.D.; Department of Medicine, HealthPartners and University of Minnesota Medical School, Saint Paul, MN, USA (e-mail: benji@umn.edu).

\section{REFERENCES}

1. Gonzalo JD, Kuperman EF, Chuang $\mathbf{C H}$, et al. Impact of an overnight internal medicine academic hospitalist program on patient outcome. J Gen Intern Med. doi:10.1007/s11606-015-3389-0.

2. Hostetter $\mathbf{M}$, Klein $\mathbf{S}$. Using patient-reported outcomes to improve health care quality. Quality Matters (Dec-Jan 2011/2012).

3. Haber LA, Lau CY, Sharpe BA, Arora VM, Farnan JM, Ranji SR. Effects of increased overnight supervision on resident education, decision-making, and autonomy. J Hosp Med. 2012;7:606-10. doi:10.1002/jhm. 1959.

4. Whalen T, Wendel G. New supervision standards: discussion and justification. In: Philibert I, Amis Jr S, eds. The ACGME 2011 duty hour standards: enhancing quality of care, supervision, and resident professional development. Chicago, IL: ACGME; 2011:39-45.

5. Hanson JT, Leykum LK, Pugh JA, McDaniel RR. Nighttime clinical encounters: how residents perceive and respond to calls at night. J Hosp Med. 2015;10:142-6. doi:10.1002/jhm.2315. 